\title{
A JUDICIALIZAÇÃO DA SAÚDE: ATORES E CONTEXTOS DE UM FENÔMENO CRESCENTE
}

\author{
THE JUDICIALIZATION OF HEALTH: ACTORS AND CONTEXTS OF A GROWING \\ PHENOMENON
}

\section{Lucas Oliveira Faria}

Procurador do Município de Ribeirão Preto. Bacharel em Direito pela Universidade Estadual Paulista "Júlio de Mesquita Filho" (Unesp), Faculdade de Ciências Humanas e Sociais, Franca. E-mail: lucasfaria.direitounesp@gmail.com

\section{Patrícia Borba Marchetto}

Doutora em Direito pela Universidad de Barcelona, docente do Departamento de Administração Pública da Faculdade de Ciências e Letras de Araraquara (FCL/Ar-UNESP) e do PPGD/Direito da Universidade Estadual Paulista (Unesp), Faculdade de Ciências Humanas e Sociais, Franca. E-mail: pmarchetto@fclar.unesp.br

Recebido em: 10/01/2019

Aprovado em: 23/07/2020

RESUMO: A judicialização da saúde, por certo, é uma dentre as inúmeras problemáticas geradas pelo advento da constitucionalização do direito, característica do modelo constitucional adotado e das atuações dos poderes institucionais no Estado Democrático de Direito, seja pela ausência de uns ou pela forte presença de outros. Este artigo busca analisar o panorama geral do fenômeno da judicialização da saúde e entender, com base em bibliografia especializada, a problemática, com fins de estimular o debate na busca de uma solução favorável à efetivação do direito constitucional à saúde.

Palavras-chave: Judicialização. Saúde. Atores. Decisões judiciais.

ABSTRACT: The judicialization of health, of course, is one of the most problematic createad by the advent of the constitutionalization of the law, characteristic of the constitutional model adopted and the actions of the institutional powers in the Democratic State of Right, either by the absence of one or by the frequent present proceeding of others. This article wants to analyze the geral perspective of the phenomenon of health judicialization and understand, based on specialized bibliography, the problematic, for purposes of encourage the debate in the search for a favorable solution to the realization of the right to health.

Keywords: Judicialization. Health. Actors. Court decisions.

SUMÁRIO: Introdução. 1. A judicialização da saúde: Uma realidade frequente e de muitas faces 2. A atuação do Judiciário na garantia da saúde pública 3. Advocacia, indústria farmacêutica e

Revista de Direito Brasileira | Florianópolis, SC | v. 26 | n. 10 | p. 161-177 | Mai./Ago. 2020 
médicos: heróis ou vilões? 4. O risco do "judge hero": o caso da fostoetalonamina 5. A recomendação 31 do Conselho Nacional de Justiça - Uma resposta do judiciário à judicialização excessiva. Conclusão. Referências.

\section{INTRODUÇÃO}

Desde a constituinte, em 1988, que a concepção acerca dos direitos fundamentais teve significativa alteração no Brasil, com destaque para o fortalecimento do Poder Judiciário na busca da efetivação destes direitos.

Os direitos fundamentais sociais, por sua vez, deixaram de ser interpretados como simples promessas e passaram a ser entendidos como de eficácia imediata pelas cortes judiciais. Nesta perspectiva, destaca-se o direito à saúde que, por sua concepção ampla, calcada em universalidade e integralidade, passou a gerar inúmeras decisões judiciais obrigando o Estado a fornecer diversos insumos com fins de tutelar a boa saúde dos cidadãos.

É certo que a referida atuação acaba por gerar significa discussão no meio jurídico, principalmente pelo numeroso volume de demandas judiciais e, ainda, pelas incontáveis distorções que pode causar.

Faz-se necessária uma análise sobre as diversas complexidades desse reflexo da ordem constitucional brasileira e da incessante busca de efetivação do direito à saúde, buscando-se entender em que medidas esta realidade contribui para tal intento e em que prismas acaba por prejudicá-lo.

Busca-se, portanto, a partir de um método dedutivo, executado por técnica de levantamento bibliográfico por meio de levantamento literatura especializada e atualizada, contribuir para a análise, de forma pormenorizada, do fenômeno da judicialização da saúde no Brasil e julgar, se possível, suas consequências na efetivação da saúde pública.

\section{A JUDICIALIZAÇÃO DA SAÚDE: UMA REALIDADE FREQUENTE E DE MUITAS FACES}

O fenômeno da judicialização pode ser entendido como a atuação do Judiciário de modo a realizar direitos que haveriam de ser conferidos a partir da tomada de decisões por parte do Executivo e do Legislativo.

A judicialização não deve ser confundida com o ativismo, já que aquela decorre do dever inarredável do Estado de prestar a tutela jurisdicional, enquanto este se dá pela postura proativa do magistrado (GANDINI;BARIONE;SOUZA, 2010) que vem a decidir a partir de suas próprias convicções, invadindo o âmbito de atuação dos outros poderes.

Deste modo, a judicialização, principalmente no cenário brasileiro, passa a ser uma consequência do modelo constitucional adotado (BARROSO, 2009), que acaba por constitucionalizar inúmeros assuntos e atribuir ao Judiciário a função indesviável de sanar qualquer lesão ou ameaça a direito, promovendo efetividade as promessas constitucionais, como no caso do direito à saúde pública.

The use of the term "Judicialization of Health" took place in the early 1900s where Brazil began to experience the effects of the new Constitutional order. So with the return of democracy and the constitutional guarantee of fundamental and social rights, various lawsuits came to court seeking the effectiveness of the promised 
rights against the failure of State obligation concerning the health care. (MARCHETTO et al, 2016, p.943) ${ }^{1}$

Assim sendo, deve-se interpretar que a atuação judicial frente à judicialização da saúde, em virtude da estrutura do sistema jurídico brasileiro, não fere, em regra, a independência dos poderes, afinal, mesmo na teoria clássica da separação de poderes há uma forma de controle denominada "checks and balances" ou "freios e contrapesos" (FALAVINHA, 2013).

No que se refere à judicialização da saúde, é notório que o excessivo incremento de demandas judiciais surge, exatamente, pelo sistema de saúde pública previsto em nosso ordenamento, principalmente pela ideia de integralidade, que é ponto nevrálgico da problemática.

A indefinição sobre os reais contornos do dever do Estado no que se refere ao oferecimento integral de serviços e produtos de saúde contribui para o incremento da judicialização da saúde no Brasil, fenômeno por meio do qual o cidadão vai ao Poder Judiciário para garantir direitos constitucionalmente garantidos de acesso universal e integral do direito à saúde. A definição sobre quais serviços e produtos que serão incorporados ao sistema público de saúde e oferecidos de forma universal constitui, assim, um momento estratégico na conformação das garantias concretas de efetivação da saúde como direito a ser preservado de forma integral. (AITH et al, 2014, p.15)

É certo que a noção de saúde adotada pelo sistema brasileiro e, inclusive, a amplitude do "direito à saúde" posto, trazem ao cidadão a expectativa de que o Estado deve oferecer todo o necessário para a garantia da saúde, entretanto, em um cenário de envelhecimento populacional e aumento de expectativa de vida, que ensejam maior demanda por serviços de saúde (NUNES, 2010), aliada a incomensurável oferta da indústria farmacêutica, que, geralmente, possui alto custo, colaboram para a intensa dificuldade de efetivação do direito à saúde, nos termos esperados pelos cidadãos, como esclarece Maria Patrão Neves:

A expressão "direito à saúde" mantém-se, todavia, ambígua, dado o âmbito alargado em que se inscreve e a formulação abstrata que o enuncia, permitindo que seja frequentemente interpretada de uma forma restritiva e distorcida como direito individual que assistiria a cada um de exigir para si a mobilização incondicional dos meios humanos e técnicos necessários para a restauração de sua saúde. Esta errônea concepção do "direito à saúde" é reforçada, no atual contexto problemático, ao ser associada aos avassaladores progressos da biomedicina, os quais, muitas vezes, por seu surpreendente ineditismo, constituem verdadeiros milagres contemporâneos. $(1999$, p.2)

Os "milagres contemporâneos" citados por Maria Patrão, característicos do avanço da biotecnologia farmacêutica, não se permitem ser acompanhados pelo sistema de saúde pública, afinal, enquanto as necessidades de saúde são praticamente infinitas e as tecnologias para resolvêlas surgem de forma desenfreada, com eficácia assegurada ou não, os recursos públicos para atende-las são finitos, e, além disso, a saúde não é o único bem que a sociedade tem interesse de usufruir (FERRAZ;VIEIRA, 2017), não se permitindo olvidar que o direito à saúde não corresponde ao direito a tudo se apresenta disponível no mercado (GADELHA, 2014).

É certo que, ainda que haja finitude de recursos, há severa crítica a forma como os recursos são destinados e aplicados à saúde pública brasileira, afinal, de acordo com especialistas na área

\footnotetext{
1 "O uso do termo "judicialização da saúde" ocorreu no início dos anos 90 onde o Brasil começou a experimentar os efeitos da nova ordem constitucional. Assim, com o retorno da democracia e da garantia constitucional dos direitos fundamentais sociais, varias ações judiciais chegaram aos tribunais buscando a eficácia dos direitos prometidos contra o fracasso da obrigação estatal sobre os cuidados de saúde." (tradução nossa)
}

Revista de Direito Brasileira | Florianópolis, SC | v. 26 | n. 10 | p. 161-177 | Mai./Ago. 2020 
do direito financeiro, o problema da judicialização da saúde nasce no orçamento que não prioriza os valores constitucionais que a Constituição elencou, havendo certa ausência de vontade do Estado na efetivação dos direitos sociais, que opta por aplicar a receita pública em outras demandas.

Estas incongruências orçamentárias são elucidadas por Marcos Abraham, durante exposição no $2^{\circ}$ Congresso Internacional de Direito Financeiro, com base em certos dados, tais como o emprego, de acordo com a Secretaria Social da Presidência da República, de R \$ 671 milhões em publicidade institucional em 2013, enquanto o custo da judicialização, no mesmo ano, estava em 500 milhões, ou ainda, os dados do Portal Transparência que elucidam gasto de 1 bilhão 282 milhões de reais em passagens aéreas e despesas com locomoção do serviço público federal enquanto a judicialização da saúde tomou aproximadamente 800 milhões do orçamento. (ABRAHAM, 2015). A crítica de Abraham é ainda reforçada por outros autores, como se nota:

Para ter dimensão, o gasto federal em saúde pública, no Brasil, na esfera federal, não representa $2 \%$ do Produto Interno Bruto (PIB). Ademais, dados da Organização Pan-Americana da Saúde (OPAS) apontam que o gasto com saúde pública como proporção do PIB brasileiro, com base na medição do valor total da economia, nas três esferas de governo, representa 3,7\%. (SOARES, 2013, p.104)

Ainda que existam incongruências orçamentárias, e que estas necessitem ser corrigidas pela atuação política consciente, ética e compromissada com a realização dos valores constitucionais, há de se concordar que se torna muito dificultoso ao Estado, principalmente com o aumento da expectativa de vida, maior avanço tecnológico e excessiva medicalização atender a todas as demandas existentes.

Os estudos recentes são claros no sentido de que o principal objeto de litígio nas cortes brasileiras são os medicamentos (MEDEIROS;DINIZ;SCHWARTZ, 2013), atribui-se essa realidade, também, a ideia de que o medicamento, muitas vezes, é diretamente associado como sinônimo de saúde.

Isso explica, pelo menos em parte, o porquê do direito à saúde ser fortemente atrelado ao direito de acesso a medicamentos, o aumento percentual de gastos com medicamentos em relação ao orçamento total, bem com o aumento de ações judiciais que têm como pedido principal a adjudicação desses bens. (CASTRO, 2012, p.211)

É certo que a dispensação de medicamentos faz parte da política pública de saúde e é devidamente regulada pelo poder público, inclusive, o Ministério da Saúde publica a Relação Nacional de Medicamentos Essenciais (RENAME), de acordo com a Portaria GM/MS 507/1999, com o objetivo de racionalizar a saúde pública no Brasil e servir de base para que os estados e municípios elaborem suas listas (CARDOSO, 2017).

$\mathrm{O}$ argumento frequente da administração pública é de que o Judiciário não deveria atuar de modo a garantir ao cidadão medicamentos que estejam fora das listas disponibilizadas pelo Poder Público, entretanto, não é o que acontece, afinal, como se disse acima, os avanços tecnológicos fazem surgir inúmeros fármacos inovadores que, na maioria das vezes, não constam das listas disponibilizadas, inclusive, há entendimento doutrinário de que as listas não deveriam ser fator determinante para a disponibilização de um medicamento.

Como se percebe, de 1977 até 2011, não foram muitas as atualizações das listas oficiais de medicamentos fornecidos pelo Poder Público. Além disso, a despeito das atualizações realizadas, o número de medicamentos constantes da lista também apresentou pouca variação - eram 300 medicamentos em 1977 e em 2010 são 335 medicamentos. Por conta disso, é que defendemos a tese de que o direito ao 
medicamento deve ser satisfeito toda vez que este se constituir no mínimo existencial do caso concreto, sendo irrelevante o fato dele pertencer ou não à lista oficial RENAME. (CASTRO, 2012, p.217)

Inclusive, é indispensável destacar que organizações governamentais, quase que de forma unânime, já elucidaram que a lista de medicamentos que direciona o SUS encontra-se desatualizada, principalmente no que se refere aos medicamentos para tratamento das chamadas doenças raras (VALLE, 2011).

Quanto à atuação judicial para conferir medicamentos e serviços de saúde que já estão previstos na política pública do SUS, a majoritária doutrina e jurisprudência entendem que se faz correta, visto que o judiciário apenas atua para garantir o que está previsto.

A maior discussão surge quando da atuação para conferir tratamentos que não fazem parte da política pública de saúde. Ao mesmo tempo em que se afirma haver uma atuação do judiciário, na maioria das vezes em caráter individual, para conferir medicamento que não se adequa aos critérios do Poder Público para dispensação, o que geraria atendimento não isonômico entre os cidadãos e desorganizaria a gestão administrativa, também se diz que a atuação do Judiciário deve buscar sanar a ineficiência do Estado em garantir o adequado atendimento para tutela da saúde dos cidadãos que, na maioria das vezes, não possuem políticas públicas que coadunem com suas moléstias.

No âmbito da saúde, a judicialização se consolidou como resposta a um contexto marcado pela exclusão no acesso aos serviços de saúde e morosidade dos poderes executivo e legislativo em satisfazerem de forma efetiva as demanda acerca do acesso às ações e serviços de saúde. (COSTA, 2017, p.141)

É certo que a atuação judicial já foi responsável, no início dos anos 90, a impulsionar o Poder Público a criar políticas públicas mais eficientes para a dispensação de medicamentos para combater o HIV/Aids, em virtude da imensa judicialização de tais insumos. As políticas públicas criadas colaboraram, inclusive, para o Brasil tornar-se nação referência no tratamento da AIDS, nos dias atuais.

Uma vez criada a Lei 9.313/96, que garante a distribuição gratuita e universal desses medicamentos, as demandas passaram a ser acolhidas pelo Judiciário pressionando o Executivo a se planejar para efetivamente prover a medicação, o que acabou ocorrendo. O Programa Nacional DST/Aids é visto mundialmente como modelo de assistência e atenção aos pacientes HIV/Aids. (CYRILLO;CAMPINO, 2010, p.33)

Todavia, não se pode cair no equívoco de imaginar que a atuação do judiciário apenas possui uma face benéfica, sob pena de não analisar o fenômeno em sua totalidade, afinal, ainda que o Judiciário tenha total legitimidade para interver quando da negação de efetivação do direito à saúde por ineficiência ou omissão do Poder Público, é certo que essa atuação deve ser em caráter excepcional e de forma a sopesar adequadamente o interesse individual em face da coletividade (RAMOS, 2017).

Caso a atuação judicial não seja feita de forma comedida e com alto rigor técnico, o que não vem acontecendo em inúmeras situações, poderá ocorrer um total colapso do sistema, como se esclarece: "O sistema, no entanto, começa a apresentar sintomas graves de que pode morrer da cura, vítima de excesso de ambição, da falta de critérios e de voluntarismos diversos." (BARROSO, 2009, p.35)

A judicialização excessiva, por óbvio, pode provocar a não realização prática da Carta Constitucional, prejudicando a realização do direito à saúde de uns pela realização do direito à saúde de outros (BARROSO, 2009). 
É certo que os inúmeros recursos realocados do orçamento para garantir o cumprimento das decisões judiciais prejudicam, sobremaneira, o cumprimento das políticas públicas já estabelecidas, afinal, são inúmeras as decisões, todos os dias, ensejando gasto elevadíssimo ao erário.

A título de exemplo, menciona que somente no Estado de São Paulo o governo estadual responde a 50.700 processos judiciais, envolvendo gastos na ordem de $\mathrm{R}$ \$ 114 milhões por mês no cumprimento das demandas das pessoas que recorrem à justiça. Dessa forma, a judicialização da saúde constitui um dos grandes desafios para a gestão das ações e serviços públicos de saúde no país. (SILVA, 2017, p.208)

Muitas das decisões do Judiciário garantem o direito à saúde de cidadãos, entretanto, muitas outras, conferem aos litigantes insumos que não são e nem deveriam ser oferecidos pelo Poder Público, mas, em razão da falta de critérios dos magistrados, acabam se tornando obrigação para o Estado.

No entanto, a falta de critérios do Poder Judiciário, aliada a poucos investimento na saúde pública e à constante negativa por parte do Poder Executivo em fornecer medicamentos, gera a proliferação de decisões que ocasionam uma despesa incomum aos cofres públicos, condenando a administração pública ao custeio de tratamentos descabidos ou mesmo ao fornecimento de medicamentos experimentais, de eficácia duvidosa, associado a terapias alternativas. (SOARES, 2013, p.108)

Deve-se, portanto, buscar conciliar as atuações de Judiciário, Executivo e Legislativo para que as prestações se tornem eficientes, uniformes e igualitárias, garantindo acesso a todos os cidadãos, e não apenas aqueles que batam as portas da Justiça (MASTRODI;FULFULE, 2017).

O Supremo Tribunal Federal, em decisões recentíssimas, busca trazer balizas capazes de atenuar possíveis danos ao planejamento público nas decisões judiciais relativas à judicialização da saúde. Cabe citar aqui dois leading cases julgados pela corte, quais sejam o RE 657718/ MG em maio de 2019, assim como a STP 455/RS em 10 de julho de 2020.

O primeiro foi julgado pelo Tribunal com repercussão geral reconhecida em que se fixou tese segundo a qual não é obrigação do Estado fornecer medicamentos experimentais, ainda que seja possível a concessão de medicamento sem registro na ANVISA, desde que configurada a mora irrazoável da agência reguladora na análise do pedido e haja pedido de registro no Brasil - desde que não se trate de doenças raras e ultrarraras -, e haja registro em agências estrangeiras, sem que exista substituto terapêutico no Brasil.

Outro importante passo na decisão em questão é que o STF entendeu que as ações que demandem medicamentos sem registro na ANVISA devem ser propostas em face da União, o que acaba por trazer certa organização quanto à repartição de atribuições no que se refere ao fornecimento de medicamentos, principalmente pela possibilidade de medicamentos sem registro na ANVISA poderem representar alto gasto aos cofres públicos que pode ser melhor absorvido pelo ente federativo que concentra o maior potencial arrecadatório.

A decisão recente do mês de Julho de 2020, ainda que em caráter liminar e decorrente do Presidente da Corte Ministro Dias Toffoli, traz também o intento de organizar a repartição de atribuições no tocante à obrigação de fornecimento de medicamentos.

O Presidente da Corte, no julgamento da Suspensão de Tutela Provisória citada, reforçou o entendimento do Tribunal de que há solidariedade entre os entes para o atendimento das demandas prestacionais de saúde, competindo a autoridade judicial direcionar o cumprimento conforme as regras de repartição de competências e determinar o ressarcimento a quem suportou o ônus financeiro, conforme fixado no Tema 793/STF. 
A novidade é que o presidente da Corte passa a delimitar melhor como deve ser observada a repartição de competências, trazendo a ideia de que deve haver uma hierarquização dos atendimentos de acordo com o grau de complexidade, de modo que os mais complexos estarão a cargo da União e, caso outros entes tenham arcado com esse ônus liminarmente, deverão pela União serem ressarcidos.

Ainda não se sabe se a presente decisão será reafirmada pelo plenário, mas, por certo, busca aclarar e trazer segurança jurídica e orçamentária aos Estados e Municípios quanto à repartição de obrigações das demandas judiciais de saúde.

Analisar-se-á, a seguir, o fenômeno da judicialização da saúde de forma mais pormenorizada, começando por uma visitação ao modo de atuação do Judiciário, na difícil tarefa de garantia da saúde pública.

\section{A ATUAÇÃo DO JUDICIÁRIO NA GARANTIA DA SAÚDE PÚBLICA}

São inúmeros os autores que já analisaram compilados de decisões judiciais na área da saúde, em diversos estados da federação, desde o primeiro grau até o Supremo Tribunal Federal, chegando a interessantíssimas conclusões que mostram, em geral, a forma como a Justiça encara o direito do cidadão à saúde pública e atua na tentativa de efetivá-lo. Após exaustivo levantamento bibliográfico sobre o tema, se fará uma sucinta abordagem expositiva de modo a facilitar ao leitor o entendimento da referida atuação judicial.

Nota-se que as ações predominantes, principalmente no tocante à judicialização em matéria de medicamentos, são aquelas que buscam fármacos não constantes nas relações oficiais, o que leva a uma atuação do Judiciário que não coaduna com as políticas públicas estabelecidas pelo SUS (CARDOSO, 2017), como se vê:

A representatividade desse volume de recursos pode ser mensurada a partir de outros relatos na literatura, como no estado de São Paulo, onde foi levantado que, em 2006, 77\% dos medicamentos solicitados por via judicial não pertenciam ao elenco de medicamentos fornecidos pela Secretaria Estadual de Saúde ou pelo Ministério da Saúde. No estado de Minas Gerais também foi possível observar que em $75,5 \%$ dos casos avaliados os medicamentos solicitados por processos judiciais durante o período de 2005 a 2006, não pertenciam ao elenco padronizado da RENAME e 56,7\% não estavam contemplados em programas da SES/MG. (SILVA;ALMEIDA;PESSÔA, 2017, p.116)

É certo que, como dito acima, há literatura que defende que o respeito as listas de medicamentos não deve ser absoluto, podendo, em certos casos, ocorrer a atuação judicial para conferir medicamentos que não estejam previstos nas listas, mas que sejam indispensáveis a garantia do mínimo existencial dos postulantes. Ocorre que para a sustentação dessa ideia deve haver, por parte do Judiciário, a busca da configuração de um grande ônus argumentativo por parte do postulante para que se confira um medicamento fora das listas, o que não parece estar ocorrendo, de acordo com os dados supratranscritos. Note-se, ainda, que há dados que mostram que o maior potencial de gastos acaba ocorrendo com poucos medicamentos, mas que possuem altíssimo custo, como se vê:

Ainda, de 15 medicamentos/ano foram identificados 7 medicamentos (Alfagalsidade, Alfaglicosidade, Betagalsidase, Eculizumabe, Galsufase, Idursulfase e Laronidase) que foram objeto de ação judicial nos quatro anos analisados (2011-2014). Estes 7 medicamentos correspondem a $R \$ 1,45$ bilhão do 
orçamento federal no período o que significou $87 \%$ do gasto total das ações estudadas. (NOGUEIRA;CAMARGO, 2017, p.126)

A determinação judicial para a compra de medicamentos deste tipo gera duas deturpações, a primeira delas ocorre pela necessidade de ser realizada em prazo exíguo e sem planejamento, o que causa maior distorção na gestão pública, já que reduz o poder de compra do Estado, fazendo com que este tenha que pagar mais caro em um produto que, se fosse adquirido por meio de planejamento e tempo adequados poderia custar menos; a segunda deturpação surge pelo fato de ocorrerem muitas aquisições em caráter individual, apenas àqueles que tem a possibilidade de bater às portas do Judiciário. A judicialização da saúde, como se nota, não privilegia a tutela coletiva, que poderia, inclusive, não prejudicar tanto a gestão pública, já que se o Judiciário fosse provocado para conferir um certo medicamento, que apresenta alto índice de judicialização em caráter individual, na esfera coletiva, ou seja, se o Poder Público fosse instado a adicionar o medicamento em suas listas, talvez, a compra pudesse ocorrer de forma mais adequada ao interesse público e, claro, a dispensação do fármaco seria a todos aqueles que dele necessitassem e não apenas aos que chegassem ao Judiciário, entretanto, não é assim que acontece.

A receptividade do Poder Judiciário tem se mostrado diversa em relação às ações demandando direitos individuais ou direitos coletivos. Em geral, obtém-se mais resultados em pleitos individuais, onde o processo diz respeito à compra de um bem específico ou ao pagamento de um procedimento médico-hospitalar. Nos casos dirigidos pelo Ministério Público na área da saúde, o Poder Judiciário tem evitado opinar sobre estas questões, possivelmente porque tais ações incidem diretamente na condução das políticas públicas para o setor e demandam maior gasto público. (MACHADO, 2008, p.78)

Como se não bastasse a problemática exposta acima, é aferível, ainda, que a atuação dos magistrados reforça uma tendência de deferimento de liminares, como no caso do Estado de São Paulo, em que de todas as decisões judiciais analisadas, 93,5\% das interlocutórias concederam liminar compelindo o Estado a fornecer o medicamento pleiteado (MARQUES; DALLARI, 2007).

A ocorrência frequente das liminares gera grande crítica ao fenômeno da judicialização da saúde, principalmente por estas possuírem caráter satisfativo e por, provavelmente, não privilegiarem o ônus argumentativo citado acima para que medicamentos fora das listas sejam conferidos aos indivíduos.

O deferimento quase automático da liminar, em caráter satisfativo, sem exame da situação fática, expressa esse fenômeno da desconfirmação, no sentido de que a lista de medicamentos não serve de parâmetro para a apreciação do caso ou julgamento da procedência do pedido. Não se trata, portanto, de uma decisão baseada na inexistência ou deficiência da política pública, que caracterizam a omissão do Poder Executivo. A massificação do tipo de resposta judicial, medida liminar, aponta que o conteúdo da política (as listas) deixa de ter alcance para o regramento de grande parte dos casos concretos postos em exame. (BUCCI, 2017, p.72)

Além de ocorrerem inúmeros deferimentos liminares em demandas relacionadas a saúde, até mesmo nos tribunais o Judiciário não se atém a argumentos orçamentários, possuindo a tendência de ver o direito à saúde como o direito a uma prestação ilimitada, como exemplifica:

Assim, na $2^{\mathrm{a}}$ Região, não foram localizados precedentes que eventualmente tivessem negado o fornecimento de medicamentos, ou que tivessem deduzido fundamentação diferente da invocação genérica da Constituição Federal. A 
tendência é ver um direito a prestação ilimitada, sem necessidade de prévio questionamento ou consulta ao médico do SUS. (TESSLER, 2010, p.76)

A referida constatação é tida, também, pela mesma autora, como majoritária em outros tribunais analisados, tais como o da $4^{\mathrm{a}}$ e da $5^{\mathrm{a}}$ regiões. O posicionamento do Supremo Tribunal Federal também não se diferencia muito do já explanado, afinal, observou-se, em pesquisa recente, que $100 \%$ dos recursos apresentados tiveram o provimento negado com a manutenção da decisão condenatória, não entendendo o STF que tenha ocorrido violação ao princípio da separação dos poderes, nem mesmo violação ou lesão à ordem econômica (COSTA, 2017).

Em levantamento jurisprudencial com foco no Estado da Bahia, feito no ano de 2017, notou-se que os principais fundamentos das decisões judiciais são principiológicos, levando em conta a garantia integral do direito à saúde, como dever do Estado e direito de todos, com base no princípio da integralidade (RAMOS, 2017). Muitas vezes, inclusive, os pedidos formulados são acatados da forma como são realizados, de forma genérica, como um cheque em branco.

Na maioria das vezes as sentenças comumente acatam o pedido formulado "nos termos da petição inicial", o que inclui o pedido genérico (todo e qualquer medicamento que o autor venha a necessitar) e perene (condena-se a fornecer o medicamento que ele precisar no futuro) sem que tenha sido discutido e analisado durante todo o processo o caso clínico que originou o pedido e sem levar em conta que o medicamento pode ser substituído ao longo do tempo. Não se exigiu um relatório médico que mostre a evolução da doença, os tratamentos utilizados, a falha destes medicamentos em controlar os sintomas e a doença, a justificativa para utilização da medicação pleiteada e o porquê de não se tentar um substituinte terapêutico. Não se faz qualquer perícia e não se discute a real necessidade do medicamento no caso concreto. (CASTRO, 2012, p.234)

Deste modo, reacende-se a preocupação já levantada por Luís Roberto Barroso de que o sistema pode morrer da cura, afinal, o total desrespeito a política pública já estabelecida sem o devido ônus argumentativo para tanto, não só por parte dos postulantes, como também por parte da fundamentação das decisões judiciais, gera grande preocupação, não só por gerar grande ônus ao erário público e desregular a gestão administrativa, mas também por, vez ou outra, privilegiar interesses espúrios que não coadunem com a garantia da saúde pública.

\section{ADVOCACIA, INDÚSTRIA FARMACÊUTICA E MÉDICOS: HERÓIS OU VILÕES?}

Em virtude do mencionado despreparo do Judiciário, que resulta em grande voluntarismo na área da saúde, há discussão quanto ao papel da advocacia, da indústria farmacêutica e, inclusive, dos médicos no fenômeno da judicialização da saúde.

É certo que, em um cenário em que a maioria dos pedidos feitos e deferidos na área de medicamentos referem-se a fármacos ainda não presentes na lista de dispensação do SUS, é economicamente viável para a indústria farmacêutica a judicialização da saúde, assim como também favorece a advocacia privada que possui grande volume de trabalho e, por consequência, relevantes ganhos.

Ainda no ano de 2016 foi amplamente noticiado que o Ministério da Saúde suspeitava de uma suposta rede envolvendo médicos, pacientes, advogados e juízes em uma movimentação chamada de "máfia da judicialização".

O Ministério da Saúde iniciou uma investigação sobre a existência da "máfia da judicialização". Há um mês, uma equipe da assessoria jurídica da pasta foi destacada para cruzar dados de médicos, pacientes, advogados e juízes. A ideia é 
identificar grupos que tenham atuado ao longo dos últimos anos para obter vantagens indevidas nas ações que cobram do poder público remédios não oferecidos pelo Sistema Único de Saúde. (SUS). (FORMENTI, 2016)

A literatura especializada em judicialização da saúde já aponta inúmeras incongruências e possíveis relações entre tais setores, principalmente destacando os interesses da indústria farmacêutica em uma judicialização desenfreada, que desloca recursos públicos para a aquisição de medicamentos de alto custo, como se verá a seguir.

Já no ano de 2007, Silva Badim Marques e Sueli Gandolfi Dallari destacavam sobre a realidade da judicialização da saúde pública e da grande influência do setor farmacêutico neste fenômeno, pela experiência do Estado de São Paulo, as autoras conseguiram averiguar que em inúmeras demandas, eminentemente individuais, não só os litigantes eram representados por advogados privados, como os fármacos eram denominados de acordo com o nome do laboratório e a marca.

Todos os autores processuais se enquadravam na categoria de autor individual, $67,7 \%$ representados por advogados particulares e destes, $23,8 \%$ possuíam o apoio de associações. Em 35,5\% dos processos apareceu expressamente o nome do laboratório farmacêutico no pedido do autor e, em 77,4\% dos casos, o autor requereu pelo menos um medicamento ou insumo (dos demais pleiteados) de uma determinada marca, sobrepondo o nome fantasia do medicamento ou insumo ao seu nome genérico. (MARQUES;DALLARI, 2007, p.104)

Um levantamento mais recente, que teve como foco a cidade de Campinas, concluiu que 86,5\% das ações tem patrocínio de advogado particular, ainda que em 99,5\% dessas ações seja utilizada a justiça gratuita. Destes advogados $89 \%$ afirmaram ter cobrado honorários e todos foram uníssonos ao dizer que não possuíam clientes em situação de pobreza (SILVA;PIMENTA, 2017).

É ainda interessante que houve estudo, focado nos medicamentos para mucopolissacaridose, que representam fármacos de custo elevado, na maioria das vezes fora das listas do SUS, demonstrando que existiria algum tipo de rede que colocasse em contato pacientes e advogados.

Há uma altíssima concentração de casos em poucos advogados privados. Por outro lado, não há forte correlação entre o local de residência ou a origem dos pacientes e o local de atuação desses advogados concentradores. É pouco provável que a contratação atomizada de advogados privados por uma população geograficamente dispersa gerasse um padrão distributivo desse tipo, o que sugere a existência de algum tipo de rede que coloca em contato pacientes e advogados. (MEDEIROS; DINIZ; SCHWARTZ, 2013, p.1.094)

Os mesmos autores chegaram à conclusão de que um único advogado seria responsável por processos de 70 pessoas, o correspondente a $36 \%$ da totalidade, o que em conjunto representava um gasto para o Poder Público no montante de 77 milhões de reais.

Foi, inclusive, apontado que há organizações não governamentais que se prontificam em interligar advogados e pacientes, estando estas sobre a influência direta de empresas farmacêuticas, na escolha dos médicos e do tratamento adotado.

Os resultados evidenciaram também a existência de relações entre os advogados e diversos tipos de organizações, incluindo empresas da indústria farmacêutica, clínicas, médicos e associações sem fins lucrativos. Destaque-se que as clínicas e as empresas farmacêuticas podem desenvolver mecanismos para estimular a orientação dos advogados para a litigância, bem como a divulgação de 
informações que lhes é mais favorável por meio, inclusive, das próprias associações sem fins lucrativos. Cabe lembrar que essas relações podem estar envolvidas em um processo bastante lucrativo para o setor privado. (SILVA;PIMENTA, 2017, p.220)

Todos esses indícios chamam a atenção para uma suposta utilização do Judiciário para satisfazer os interesses da indústria farmacêutica, que força o Estado a fornecer seus medicamentos com urgência e, ainda, sem estes estarem devidamente incorporados ao sistema de saúde, ou seja, a judicialização funciona como uma via rápida para a incorporação das novidades farmacêuticas ao sistema público (FALAVINHA, 2013). Entretanto, esta incorporação rápida gera inúmeras críticas, não só pelo alto custo e por seu intenso potencial de desregulamentação da máquina pública, mas também por privilegiar a elite populacional.

A crítica da judicialização como ferramenta das elites surge pelos argumentos de que a maioria das receitas médicas dos medicamentos não registrados no SUS surgem por meio de clínicas privadas e envolvem pacientes que não utilizam o sistema público para outros serviços, apenas acionando-o por meio do Judiciário para garantia de fármaco determinado.

As ações da espécie são movidas em especial por pessoas que não querem e nem precisam, via de regra, utilizar todos os serviços do SUS, mas apenas alcançar o medicamento principalmente ou alguma terapia dispendiosa. Apresenta-se com prescrição de médico particular e buscam um medicamento não disponibilizado pelo SUS. Tem, pois, informação e relações privilegiadas, muitas vezes um plano de saúde. (TESSLER, 2010, p.99)

Quanto à esta interpretação não se poderia deixar de apresentar divergência. É certo que a previsão constitucional da saúde pública brasileira consiste em assegurar um direito de todos, universal, inclusive, o sistema de saúde é financiado por impostos, bem como por contribuições sociais, não sendo lógico que um cidadão com boas condições financeiras não tivesse o devido atendimento (CASTRO, 2012). Há ainda, relevante crítica a ideia de que o SUS seria uma política direcionada, única e exclusivamente, aos hipossuficientes.

A luta pelo direito à saúde, como um direito das pessoas pobres, valoriza a saúde apenas como um direito que deve ser satisfeito no campo da assistência social, esvaziando-a de seu conteúdo de direito social e individual a ser garantido pelo poder público a qualquer cidadão. (CARVALHO;SANTOS, 2006, p.41)

O SUS deve atender a todos que dele necessitem, disto não se pode discordar, sob pena de relativizar os dispositivos constitucionais que a duras lutas o consagraram. Entretanto, satisfazer a todos não quer dizer dar tudo a todos, disto sim deve-se discordar. Com informações sobre os inúmeros atores envolvidos na judicialização da saúde, nota-se o quão fundamental é a necessidade de qualificar o Judiciário pra que este possa, quando da sua atuação, não ser forçado a agir de forma não articulada, satisfazendo interesses corporativos em razão do desconhecimento, sob pena de enriquecer oligopólios e sacrificar a saúde pública, afinal, os gastos com os fenômenos da incorporação tecnológica podem ser fatais ao orçamento da saúde, como se nota.

Admitindo que o SUS trate um quarto das pessoas portadoras de hepatite $\mathrm{C}$ com o interferon peguilato (a versão mais moderna e mais cara), o gasto com o tratamento delas (apenas $0,25 \%$ da população brasileira) representaria $64 \%$ do orçamento do Ministério da Saúde de 2006! O direito de 0,25\% da população estaria garantido, mas e o direito dos restantes $99,75 \%$ ? Como fica o quesito equidade? (CYRILLO;CAMPINO, 2010, p.35) 
Conclui-se, portanto, que independente das intenções dos atores envolvidos na judicialização da saúde, deve-se buscar o desenvolvimento de um judiciário capaz de atuar de acordo com a realização do interesse público em matéria de saúde, buscando realizar os objetivos constitucionais e não privilegiar interesses da advocacia farmacêutica, sob pena de comprometer o sistema de saúde pública.

\section{O RISCO DO “JUDGE HERO”: O CASO DA FOSFOETALONAMINA}

Com toda a explanação já realizada, é importante deixar claro que a intenção aqui não é tomar um partido no sentido de ovacionar ou rechaçar completamente o fenômeno da judicialização da saúde. Entende-se, sim, que a atuação judicial na efetivação do direito à saúde pública é sim legítima e pode, sim, ser instrumento adequado para dar ao cidadão um direito que já é seu. Todavia, há de se considerar que, nem sempre a atuação judicial ocorre de forma adequada e muitas vezes, como já dito, privilegia interesses diversos daqueles do cidadão que bate às portas da justiça para ter seu direito assegurado, trata-se da dicotomia entre o juiz herói e o juiz vilão.

Logo, a figura do "juiz-herói”, capaz de influenciar de maneira positiva, na seara política, a fim de concretizar direitos na sociedade, tomou lugar para o "juizvilão", capaz de deturpar a ordem política e causar maiores desigualdades, sendo alvo de várias críticas. (FALAVINHA; MARCHETTO, 2015, p.118)

É importantíssima a reflexão do Judiciário quanto à sua atuação e ao seu papel no estado democrático de direito para que este poder, tão caro à República, não venha a se perder em seus atos. Aqui se elucidará um fenômeno bastante recente em que, ao nosso ver e sob o respaldo da boa doutrina, o judiciário prestou um desserviço à tutela da saúde.

A fosfoetalonamina foi fruto das pesquisas de um docente já aposentado do departamento de química da Universidade de São Paulo, não passou pelos testes exigidos para que pudesse ser oferecido a humanos, e estava, portanto, muito longe ser registrada pela ANVISA, sendo assim não tinha autorização para ser comercializada no Brasil, e, muito menos, fazia parte dos medicamentos a serem dispensados pelo SUS. De forma mais direta, é corretíssimo dizer que a fosfoetalonamina nem mesmo chegou a ser um medicamento (BUCCI, 2017).

Entretanto, em virtude da informação desvirtuada de que esta poderia ser capaz de curar o câncer, visto que em tratamentos com roedores teria apresentado progresso na luta contra a doença, muitos cidadãos bateram às portas do Judiciário, com fins de obrigar o laboratório de química da USP, que nem mesmo possuía a estrutura para dispensação de fármacos em grande quantidade, a fornecer a fosfoetalonamina.

Assim, para sermos precisos, impõe-se corrigir a afirmativa acima: não era apenas a crendice popular que atribuía a pílula azul os poderes de cura do câncer. Centenas (talvez milhares) de juízes, atuando desde a primeira instância até o Supremo Tribunal Federal também acreditavam nisso. Desconhecendo as imposições da razão - que se aplicam, em princípio, tanto aos processos judiciais como às pesquisas médicas - passaram por cima de protocolos há muito tempo estabelecidos na ciência, tomando como acabado o produto de experiências iniciais em um laboratório de Química. Amparados apenas no art. 196 da Constituição e em sua crença na autoaplicabilidade dos direitos fundamentais, esse grande contingente de magistrados seguiu determinando, freneticamente, à proporção de mais de mil novas liminares por mês, a entrega de cápsulas aos doentes. Parecia que a justiça havia descoberto a cura do câncer. (BUCCI, 2017, p.32) 
As inúmeras demandas judiciais e seus respectivos deferimentos liminares, com fundamentos genéricos e ignorando totalmente a realidade de que a fosfoetalonamina era uma substância que não podia ser conferida a humanos, pois, afinal, nem sequer havia ciência sobre os riscos de sua utilização, fizeram com que a Universidade de São Paulo tivesse sua estrutura seriamente comprometida, não só pelo excesso de trabalho sob o qual seu setor jurídico se deparou em um período de tempo muito curto, como também pela demanda inimaginável de produção de fosfoetalonamina imposta a um simples laboratório de química dentro de uma instituição de ensino.

Ao deferir liminares, baseiam-se os julgadores no direito à saúde do autor, bem como no "direito à esperança". Postulados de razoabilidade e proporcionalidade, bem como a obediência ao sistema normativo constitucional, são nitidamente esquecidos. (SANTOS et al, 2017, p.149)

Os casos da fosfoetalonamina são perfeitos exemplos de atuação judicial inconsequente, uma ilustração clara de como a judicialização desenfreada pode comprometer a estrutura da Administração e, até mesmo, colocar em risco a saúde dos indivíduos, ao invés de promovê-la, sob o pressuposto de garantir a esperança da cura, a qualquer custo.

Como por vezes o sistema normativo é colocado de lado para privilegiar pretensão daquele que se encontra em possível situação de fragilidade, ainda que sem evidências ou provas suficientes, e sob o risco de agravamento irreversível do quadro clínico. (SANTOS et al, 2017, p.141)

\section{A RECOMENDAÇÃO 31 DO CONSELHO NACIONAL DE JUSTIÇA - UMA RESPOSTA DO JUDICIÁRIO À JUDICIALIZAÇÃO EXCESSIVA}

Em razão da excessiva judicialização e das incongruências que, com o tempo, foram sendo questionadas na atuação judiciária para a garantia do direito à saúde, o Supremo Tribunal Federal, por ato de seu presidente, à época o Ministro Gilmar Mendes, convocou a Audiência Pública No 4 , com o objetivo de reunir especialistas para tratar do fenômeno da judicialização da saúde, com fins de otimizar a atuação judicial (VALLE; CAMARGO, 2011).

Após a realização da referida audiência pública, o Conselho Nacional de Justiça (CNJ) constituiu grupo de trabalho que culminou na aprovação, em plenário, da Recomendação $n^{\circ}$ 31/2010, com diretrizes para a atuação dos magistrados quanto às demandas judiciais que envolvessem a assistência à saúde, atribuindo aos tribunais a adoção de medidas para melhor subsidiar os magistrados na busca da maior eficiência de suas decisões envolvendo a saúde. (VERBICARO; SANTOS, 2017).

A Recomendação 31 traz consigo várias disposições, dentre elas a celebração de convênios, por meio dos tribunais, para prestar apoio técnico aos juízes quanto às demandas da judicialização da saúde. Além disso, quanto à atuação dos magistrados propriamente dita, recomenda que estes instruam suas decisões com relatórios médicos com descrição da doença por meio do CID, contendo prescrição do medicamento com a prescrição genérica e o princípio ativo, que se evite a prescrição de medicamentos não registrados na ANVISA, que ouçam os gestores antes da concessão da tutela de urgência, entre outros.

As instruções do $\mathrm{CNJ}$, portanto, buscam tornar a atuação judicial mais coerente com a garantia da eficácia do direito à saúde, evitando, portanto, o prestígio a interesses de laboratórios ou, ainda, a atuação inconsequente do "judge hero" que, como visto, pode converter-se em vilania, não se pode dizer, entretanto, que as referidas instruções foram frutíferas naquilo que se propuseram. 


\section{CONCLUSÃO}

É correto dizer que a judicialização da saúde não pode ser encarada com fatalismo, ou seja, não se faz possível, principalmente a partir de uma análise profunda do problema, dizer se tal fenômeno é maléfico ou benéfico na busca da efetivação da saúde.

É certo que a atuação judicial na busca da efetivação do direito à saúde não ocorre, exclusivamente, por uma atuação ativista do judiciário brasileiro, afinal, o próprio sistema constitucional adotado prevê a referida atuação e, por inúmeras vezes, a ineficiência ou omissão do Executivo no cumprimento das políticas públicas já estabelecidas para garantia da saúde obrigam que o Judiciário atue na efetivação deste direito.

Todavia, é inegável que também existem casos claros, como vimos, em que o Judiciário brasileiro age com certa incúria e flagrante despreparo, apenas desregulando a máquina administrativa por meio do total desprezo a política pública já estabelecida, desconsiderando os custos e a eficácia dos fármacos requeridos, colaborando para a desregulação do Sistema Único de Saúde e, assim, prejudicando a saúde dos cidadãos.

Nota-se, também, que o despreparo do Judiciário para a atuação na área do direito sanitário possibilita que este seja cooptado por interesses mercadológicos de uma indústria milionária que emparelha inúmeros atores, bastante atuantes, na promoção da judicialização da saúde e que, em que pese os esforços do Judiciário, como quando da Recomendação 31 do CNJ e de decisões recentes do Supremo Tribunal Federal, ainda falta muito para que a atuação dos juízes brasileiros se blinde de interesses espúrios e consiga, com parcimônia, preservar o direito à saúde dos cidadãos, exemplo este é o fenômeno da fosfoetalonamina, bastante recente e posterior a recomendação.

Conclui-se, portanto, que a busca de uma atuação mais coerente e, claro, eficiente, com respeito à visão global do sistema de saúde pública brasileiro passa por um fundamental diálogo institucional entre os poderes, para que o orçamento público destinado à saúde não seja utilizado com fins de favorecer oligopólios consolidados em detrimento da saúde de inúmeros cidadãos brasileiros.

\section{REFERÊNCIAS}

ABRAHAM, Marcos. Judicialização da Saúde e Limitações Orçamentárias. In. $2^{\circ}$ Congresso Internacional de Direito Financeiro. Campo Grande. TCE/MS. 2015. Disponível em https://www.youtube.com/watch?v=MMfY9ZwHxNI. Acesso em 01 Jun. 2017.

AITH, Fernando; BUJDOSO, Yasmim; NASCIMENTO, Paulo Roberto do. DALLARI, Sueli Gandolfi. Os princípios da universalidade e integralidade do SUS sob a perspectiva da política de doenças raras e da incorporação tecnológicas. Revista de Direito Sanitário. São Paulo, v.15, n.1, p.10-39, mar/jun 2014.

ALEXY, Robert. Teoria dos Direitos Fundamentais. Tradução de Virgílio Afonso da Silva da $5^{\text {a }}$ edição alemã Theorie der Grundrechte. 2 ed. Malheiros. São Paulo. 2015

BARROSO, Luís Roberto. Da falta de efetividade à judicialização excessiva: direito à saúde, fornecimento gratuito de medicamentos e parâmetros para a atuação judicial. Jurisp. Mineira, Belo Horizonte, a 60, nº 188, p.29-60, jan/mar 2009.

BARROSO, Luís Roberto. Judicialização, ativismo judicial e legitimidade democrática. Anuario Iberoamericano de Justicia Constitucional. Num 13. Madrid. 2009. P.17-32. 
BRASIL. Supremo Tribunal Federal (STF). Recurso Extraordinário 657718/MG com Repercussão Geral. Recorrente: Alcirene de Oliveira. Recorrido: Estado de Minas Gerais. Relator: Marco Aurélio Mello. Relator para Acórdão: Luis Roberto Barroso. 22 de maio de 2019.Disponível em http://www.stf.jus.br/portal/jurisprudenciaRepercussao/verProcessoDetalhe.asp?incidente $=41431$ 44\#. Acesso em 21 de jul de 2020.

BRASIL. Supremo Tribunal Federal (STF). Suspensão de Tutela Provisória 455/RS. Recorrente: Município de Santa Cruz do Sul. Recorrido: Relator do Processo n 9001265-43.2020.8.21.0020 do Juizado Especial da Fazenda Pública de Santa Cruz do Sul. Relator: Ministro Dias Toffoli.. 10 de julho de 2020. Disponível em

http://stf.jus.br/portal/diarioJustica/verDiarioProcesso.asp?numDj=177\&dataPublicacaoDj=15/07 $/ 2020 \&$ incidente $=5959286 \& \operatorname{codCapitulo}=6 \&$ numMateria $=110 \&$ codMateria $=7$. Acesso em $21 \mathrm{de}$ jul de 2020.

BUCCI, Maria Paula Dallari. Contribuição para a redução da judicialização da saúde. Uma estratégia jurídico-institucional baseada na abordagem de direito e de políticas públicas. In BUCCI, Maria Paula Dallari; DUARTE, Clarice Seixas (Orgs). Judicialização da saúde: a visão do Poder Executivo. São Paulo: Saraiva, 2017.

BUCCI, Maria Paula Dallari. O Conceito de Política Pública em Direito. In BUCCI, Maria Paula Dallari. Políticas Públicas - Reflexões sobre o Conceito Jurídico. São Paulo: Saraiva, 2006.

CASTRO, Ione Maria Domingues de. Direito à saúde no âmbito do SUS: um direito ao mínimo existencial garantido pelo Judiciário? São Paulo. Tese de Doutorado. Faculdade de Direito da USP. 2012.

CARDOSO, Cosme Santana. Análise das demandas judiciais de medicamentos: uma abordagem da realidade do Distrito Federal, Brasil. Revista Cadernos Ibero-Americanos de Direito Sanitário. Jan/Mar 2017, 6(1);P.228-246.

CARVALHO, Guido Ivan; SANTOS, Lenir. Sistema único de Saúde: comentários à Lei Orgânica da Saúde. 4 ed. Campinas: Editora da Unicamp, 2006.

COSTA, Tábata da Silva. A judicialização da saúde: as decisões do Supremo Tribunal Federal frente ao princípio da separação dos poderes. Revista Cadernos Ibero-Americanos de Direito Sanitário. Jan/Mar 2017, 6(1);P.139-152.

CYRILLO, Denise Cavallini; CAMPINO, Antonio Carlos Coelho. Gastos com saúde a questão da judicialização da saúde. In BLIACHERIENE, Ana Carla; SANTOS, José Sebastião (org). Direito à vida e à Saúde: impactos orçamentário e judicial. São Paulo: Atlas, 2010.

FALAVINHA, Diego Hermínio Stefanutto. A Judicialização da saúde e o controle judicial e políticas públicas: uma análise de como o Poder Judiciário pode contribuir para a efetivação do direito à saúde na sociedade brasileira. Franca: [s.n], 2013.

FALAVINHA, Diego Hermínio Stefanutto; MARCHETTO, Patrícia Borba. A crise entre Saúde e Poder Judiciário no Brasil através da judicialização de demandas: apresentação de outros atores responsáveis e a necessidade de um pensamento bioético. In: I CONIBDH Congresso Internacional de Bioética e Direitos Humanos, 2015, Vitoria - Espirito Santo. Anais do I 
CONIBDH ? Congresso Internacional de Bioética e Direitos Humanos. Vitoria: Faculdade de Direito de Vitoria, 2015.

FERRAZ, Octavio Luiz Motta; VIEIRA, Fabiola Sulpino. Direito à saúde, recursos escassos e equidade: os riscos da interpretação judicial dominante. Dados, Rio de Janeiro, v. 52, n. 1, p. 223-251, Mar. 2009. Disponível em

http://www.scielo.br/scielo.php?script=sci_arttext\&pid=S001152582009000100007\&lng=en\&nr m=iso. Acesso em 02 Jun. 2017

FORMENTI, Lígia. Saúde cruza dados contra suposta "máfia da judicialização”. O Estado de São Paulo. São Paulo, 16 de outubro de 2016. Disponível em http://saude.estadao.com.br/noticias/geral,saude-cruza-dados-contra-suposta-mafia-dajudicializacao,10000082413. Acesso em 19 de julho de 2017.

GADELHA, Maria Inez Pordeus. O papel dos médicos na judicialização da saúde. Revista CEJ, Brasília, Ano XVIII, n.62, p.65-70, jan/abr 2014.

GANDINI, João Agnaldo Donizeti; BARIONE, Samantha Ferreira; SOUZA, André Evangelista de. Judicialização do direito à saúde: prós e contras. In BLIACHERIENE, Ana Carla; SANTOS, José Sebastião (org). Direito à vida e à Saúde: impactos orçamentário e judicial. São Paulo: Atlas, 2010.

MACHADO, Felipe Rangel de Souza. Contribuições ao debate da judicialização da saúde no Brasil. Revista de Direito Sanitário. V.9,n.2,São Paulo, Jul/Out 2008, P.73-91.

MARCHETTO, Patrícia Borba; FALAVINHA, Diego Hermínio Stefanutto; VEIGA Jr, Helio. Judicialization of Health: The Brazilian Case and a Bioetical Review. Revista Quaestio Iuris. V.9, n.2, Rio de Janeiro, 2016, P.942-958.

MARQUES, Silva Badim; DALLARI, Sueli Gandolfi. Garantia do direito social à assistência farmacêutica no Estado de São Paulo. Revista de Saúde Pública. São Paulo, v.41, n.2, p.101-107, 2007.

MASTRODI, Josué; FULFULE, Elaine Cristina de Souza Ferreira. O problema da judicialização da saúde no Brasil: sugestão de novos rumos. Revista Quaestio Iuris. V. 10, nº2, Rio de Janeiro, 2017, P.593-614.

MEDEIROS, Marcelo; DINIZ, Débora; SCHWARTZ, Ida Vanessa Doederlein. A tese da judicialização da saúde pelas elites: os medicamentos para mucopolissacaridose. Revista Ciência e Saúde Coletiva. V.18, n.4, p.1.089-1.098, 2013

NEVES, Maria Patrão. Alocação de recursos em saúde: considerações éticas. Revista Bioética. V.7, n.2, 1999.

NOGUEIRA, Karina Pires; CAMARGO, Erika Barbosa. Judicialização da saúde: gastos federais para o Sistema Único de Saúde (SUS) entre 2011-2014. Revista Cadernos Ibero-Americanos de Direito Sanitário. Abr/Jun 2017, 6(1);P.120-132.

NUNES, Altacilio Aparecido. A avaliação econômica de fármacos e outras tecnologias em saúde instrumentalizando o poder público e judiciário para a tomada de decisão: potencialidades e 
limitações. In BLIACHERIENE, Ana Carla; SANTOS, José Sebastião (org). Direito à vida e à Saúde: impactos orçamentário e judicial. São Paulo: Atlas, 2010.

RAMOS, Edith Maria Barbosa. Argumentos dos atores processuais nas causas jurídicas sobre saúde no Estado da Bahia, Brasil. Revista Cadernos Ibero-Americanos de Direito Sanitário. Jan/Mar 2017, 6(1);P.127-138.

SANTOS, Maria Walquíria Batista dos [et al]. O caso da fosfoetalonamina. Judicialização com risco à saúde. In BUCCI, Maria Paula Dallari; DUARTE, Clarice Seixas (Orgs). Judicialização da saúde: a visão do Poder Executivo. São Paulo: Saraiva, 2017.

SILVA, Everton Macêdo; ALMEIDA, Keyla Caroline de; PESSÔA, Glaucia Silveira Carvalho. Análise de gasto com judicialização de medicamentos no Distrito Federal, Brasil. Revista Cadernos Ibero-Americanos de Direito Sanitário. Jan/Mar 2017, 6(1);P.112-126.

SILVA, Hudson Pacífico; PIMENTA, Keyla Ketlyn Passos. A atuação de advogados e organizações não governamentais na judicialização da saúde pública no Brasil: a quem será que se destina? Revista Cadernos Ibero-Americanos de Direito Sanitário. 2017 Jan./Mar, 6(1); 9-29.

SOARES, Hector Cury. A racionalização de recursos voltados às políticas públicas de saúde: a justiça geral e a justiça individual. Revista Direito e Liberdade. V.15, n.1, p.97-140. Jan/Abr 2013.

TESSLER, Marga Inge Barth. A Justiça e a Efetividade na Saúde Pública. V.1, Rio de Janeiro, 2010. Dissertação de Mestrado Profissional - Direito GV

VALLE, Gustavo Henrique Moreira do; CAMARGO, João Marcos Pires. A audiência pública sobre a judicialização da saúde e seus reflexos na jurisprudência do Supremo Tribunal Federal. Revista de Direito Sanitário. São Paulo, v.11, n.3, São Paulo, nov 2010/fev 2011, p.13-31.

VERBICARO, Loiana Prado; SANTOS, Andreza Casanova Vongrapp. A necessidade de parâmetros para a efetivação do direito à saúde: a judicialização do acesso ao hormônio do crescimento no Pará. Revista de Direito Sanitário. São Paulo, v.17, n.3, nov 2016/fev 2017, p.185-221. 